\title{
Is Chlamydia to Blame for Koala Reproductive Cysts?
}

\author{
Samuel Phillips *, Peter Timms (D) and Martina Jelocnik \\ Genecology Research Centre, University of the Sunshine Coast, Sippy Downs, QLD 4556, Australia; \\ ptimms@usc.edu.au (P.T.); mjelocni@usc.edu.au (M.J.) \\ * Correspondence: sphilli2@usc.edu.au
}

check for

updates

Citation: Phillips, S.; Timms, P.; Jelocnik, M. Is Chlamydia to Blame for Koala Reproductive Cysts? Pathogens 2021, 10, 1140. https://doi.org/ 10.3390 /pathogens10091140

Academic Editor: Lee Ann Campbell

Received: 29 July 2021

Accepted: 1 September 2021

Published: 4 September 2021

Publisher's Note: MDPI stays neutral with regard to jurisdictional claims in published maps and institutional affiliations.

Copyright: (c) 2021 by the authors. Licensee MDPI, Basel, Switzerland. This article is an open access article distributed under the terms and conditions of the Creative Commons Attribution (CC BY) license (https:// creativecommons.org/licenses/by/ $4.0 /)$.

\begin{abstract}
A significant threat to koala populations is infection from Chlamydia, which results in disease and death. Wild koalas with Chlamydia infections are admitted to wildlife hospitals and treated with antibiotics; however, up to $50 \%$ of koalas that present to wildlife hospitals do not survive. A major contributor to high mortality is the development of reproductive cysts, resulting in female infertility and euthanasia. However, the diagnosis of reproductive disease is limited to ultrasound with no further investigations. This communication highlights reports of histological and microbiological findings, the accuracy of ultrasound to necropsy reports and other possible causes for reproductive cyst development previously reported in other hosts. Our conclusions identify a significant knowledge gap in the aetiology of koala reproductive cysts and highlight the urgent need for future investigations.
\end{abstract}

Keywords: koala; Chlamydia; reproductive cysts

The koala (Phascolarctos cinereus) is one of Australia's most recognised native animals. Over the last 200 years, koala population levels have plummeted by approximately $90 \%$, with some southern populations becoming locally extinct [1]. Unfortunately, koala population levels have continued to decline due to multiple natural and anthropogenic factors, and in 2012 the koala was listed as a threatened species under the Australian Federal Environment Protection and Biodiversity Conservation Act 1999. The largest threat to koalas is habitat destruction, which has resulted in up to $80 \%$ of the koala natural habitat (eucalyptus forest) being cleared for human population growth and farming [2]. In addition to habitat destruction, a recent report of 3590 koala deaths within a single wildlife hospital over a 10-year period identified the top three reasons for koala fatalities as traffic accidents ( $36.4 \%$ of deaths), overt signs of disease (33.6\% of deaths) and dog attacks (13.8\% of deaths) [3].

A major threat to the health and wellbeing of koalas is the bacterium Chlamydia pecorum. C. pecorum is the leading cause of disease in koalas, causing high morbidity and mortality [4]. C. pecorum infections in free-ranging koalas in southeast Queensland are endemic, with clinical (chlamydial) disease observed in 30\% of surveyed animals [5,6]. Many sub-populations of koalas are on the brink of local extinction due to chlamydial disease, with estimated declines in some populations of between $55 \%$ and $80 \%$ between 1996 and 2014 [7]. A failed scheme developed in Victoria in an attempt to increase koala populations reported that translocations of healthy, Chlamydia-free koalas into areas of high Chlamydia burden resulted in increased chlamydial disease in the translocated koalas, leading to continued decline of the population [8].

C. pecorum causes urogenital and conjunctival infections in koalas with the potential to result in suffering and long-term debilitating disease [9-11]. Infections associated with the eyes cause conjunctivitis, which in severe cases results in scarring and blindness (keratoconjunctivitis) [9-11]. Infections associated with the urogenital tract can cause inflammation resulting in "wet bottom", and the development of cystitis, which in extreme cases results in ureter ascension and nephritis [9-11].

Infections and disease of the urogenital tract account for approximately $87 \%$ of all infections in some koala populations $[6,9,12]$. Chlamydia infections in the koala are treated 
with antibiotics for extended periods of time (up to 45 days) resulting in complete bacterial clearance $[9,13]$. Unfortunately, some wild koalas develop chronic, advanced disease before being found and brought to wildlife hospitals, furthermore, antibiotic treatment failure occurs, resulting in disease progression and eventual death [14]. Reproductive tract disease can progress in female koalas and result in reproductive cyst development and presumed infertility [9]. Reproductive cysts have been reported to develop during and after antibiotic treatment, even after microbiological cure. There are also reports of reproductive cysts decreasing to below detectable levels in the absence of treatment. Currently, it is not known why or how reproductive cysts in koalas develop, or why some resolve.

Reproductive cysts in koalas are commonly referred to as paraovarian or bursal cysts and are presumed to result in infertility of the koala. However, according to Jubb, Kennedy and Palmer's Pathology of Domestic Animals, ovarian cysts in other animal species are categorised into several different types. Cystic rete tubules, paraovarian cysts, inclusion cysts and anovulatory cysts of follicular or luteinizing type are difficult to determine under ultrasound and are never associated with Chlamydia infection [15]. Cystic rete ovarii have been identified in $76 \%$ of female guinea pigs and are most commonly (66-77\%) non-functional [16]. Inclusion cysts are usually diagnosed in older animals, are related to increased ovulation, and often disappear over time [17]. Anovulatory cysts are due to secondary follicles that fail to ovulate and are usually reabsorbed without complication [18] Paraovarian cysts are cysts that develop close to the ovaries and the fallopian tubes but never attach. They are usually associated with the surrounding ligaments and are also known as a paratubal cysts or hydatid cysts [19].

Host immunological responses to Chlamydia infections have been extensively studied in the mouse model where it is established that both cell-mediated immune responses involving the recruitment of macrophages, dendritic cells, natural killer cells and CD4/CD8 $T$ cells and a humoral immune response involving both plasma IgG and mucosal IgG and IgA are required for complete bacterial clearance [20,21]. It has also been established that IFN $\gamma$ restricts the growth cycle of $C$. trachomatis by depleting tryptophan through the indoleamine 2,3-dioxygenase (IDO) pathway [22-24]. However, the known specific immunological process by which the koala immune system responds to a $C$. pecorum infection contains significant gaps [25]. Recently, in vitro studies of koala PBMCs stimulated with C. pecorum elementary bodies (EBs), identified the upregulation of specific cytokines, previously shown in mouse trials to be involved in Chlamydia clearance. Cytokines TNF alpha, IL10, IFN $\gamma$ and IL17 were all shown to be highly upregulated after C. pecorum EB stimulation [26-28]. Interestingly, in vitro studies have recently identified that C. pecorum (livestock strains) are resistant to IFN $\gamma$ responses alone, a trait attributed to the near intact tryptophan biosynthesis genes [29].

It is unknown if reproductive cysts in koalas are directly related to chlamydial infections of the upper reproductive tract or due to inflammation and immunological responses to chlamydial infections of the lower reproductive tract or something entirely separate to Chlamydia infection.

The development of reproductive disease in koalas has been sporadically reported since 1981 with surprisingly concordant findings. Overall, bursal cysts form in the fallopian tubes of koalas and can involve one or both tubes. Sizes can vary between $1 \mathrm{~cm}$ and $15 \mathrm{~cm}$, and the cysts are fluid-filled. The appearance of this fluid has been reported to differ between koalas and to be straw coloured, red-brown or turbid, with differences in viscosity also reported $[30,31]$. Histological findings report that the ovaries are usually unaffected with a normal bursal lining, although some studies have reported extensive fibrous adhesions in the ovary and bursal wall space of female koalas, indicating that ovarian disease is possible [31-33]. Histological reports of fallopian tube inflammation indicate accumulations of plasma cells, lymphocytes and macrophages in the submucosa and polymorphs and macrophages in the lumen [30,31]. Other studies have reported similar findings of infiltrative immune cells from different upper and lower urogenital tissues [34,35]. A study in 1984, using radiographic techniques, reported that $43 \%$ of koalas 
$(101 / 237)$ across four states of Australia were found to have reproductive cysts with unknown aetiology (although Chlamydia was isolated) [36]. These initial reports all failed to conclusively indicate an aetiology for reproductive cyst development, although they speculated that there was the involvement of an infectious agent. The first attempts to identify an aetiology used immunohistochemical stains for Chlamydia from upper reproductive tract tissue of female koalas and identified the presence of Chlamydia in 10 koalas with active reproductive inflammation [34]. However, the same study also reported an absence of Chlamydia in koalas with tubal occlusions and high anti-chlamydial antibody titers, leading the authors to question the causal connection between ovarian cysts in the koala and chlamydial infection of the reproductive tract [34]. A further study of koalas from the South Australian Mount Lofty ranges performed histological examination on pariovarian cysts from a single koala described the cysts as thin-walled and fibrocollagenous with infrequent papilliform projections of dense fibrovascular connective tissue [37]. The same study did not report on the presence of chlamydia within the cysts nor perform any immunological tests [37].

The first reports of reproductive cyst development in koalas without inflammation of the lower genital tract were in 1989 when reproductive cysts were identified in five out of nine koalas that were suffering from cystitis but did not display inflammation within the lower reproductive tract [38]. Other than this report, there have been no other published studies on spontaneous development of reproductive cysts in koalas. Furthermore, there are also no reports of Chlamydia-specific studies from upper reproductive tract tissues or cystic fluid, and no reports of possible treatment regimens to clear disease. Considering that the Queensland government guidelines on koala treatment indicate euthanasia in cases of suspected infertility (proposed to limit habitat competition with fertile koalas) [39], the development of improved treatment regimens to combat this disease would significantly improve koala health outcomes and the chance of survival.

Several strategies are used by veterinarians to diagnose Chlamydia disease in the koala. The urogenital disease state of a koala caused by C. pecorum infection is assessed through ultrasound scanning of the internal urogenital organs (i.e., bladder, prostate, kidneys, ovaries and ureter tubes), clinical inspection of the koala's rump for evidence of a 'wet bottom' and cytological examination of urine sediment [9]. The overall health of a koala is measured using several markers including hydration status (measured by observing the tactility of the skin), gut fill (observed through abdominal palpation), lymph node enlargement (determined by palpation) and body condition scoring (measured through muscle measurement of the scapula muscles) [9]. Unfortunately, the identification of reproductive disease is limited to ultrasound imaging. This approach lacks the ability to determine the differences between chronic and acute disease. Furthermore, a recent analysis of 38 ultrasound reports and necropsy findings identified that in $44 \%$ of cases necropsy failed to conform with ultrasound diagnosis [40].

Of course, reproductive cyst development is not limited to female koalas, with naturally occurring reproductive cysts identified in rats [41,42], cynomolgus and rhesus monkeys [43,44], cows [45-47], dogs [48], pigs [49] and water buffalo [50]. Interestingly, none of these presentations were attributed to an infectious agent, but were instead related to hormone imbalance induced by many different environmental and hormonal factors, including repeated cold stress [41], increased light stress [42], increased reactive oxygen species [50-53], decreased melatonin [42] and ingestion of a high soy-based diet [54]. Furthermore, Rubio and colleges reported that the ovarian bursa of dogs can harbour bacterial colonisation in the absence of disease [55].

Women between the ages of 15 and 44 have a 5-10\% risk of developing polycystic ovary syndrome (PCOS), a disease related to hormonal disturbances, such as hyperandrogenism [56]. It appears that the development of chlamydial induced reproductive cysts outside the koala have only been sparingly reported. A single study in cows identified ovarian cysts in the presence of Chlamydia infections, although the authors state that "it is not likely that chlamydia is of causal relevance for ovarian cysts" [57]. Another study in 
1994 investigating Chlamydia infections in women also identified a significant correlation between the presence of anti-chlamydia IgG and tubular infertility, with 2 out of 10 tubal biopsies confirming Chlamydia infection [58]. The development of upper reproductive pathology, not involving the ovaries or fallopian tubes, has been described in mice and guinea pigs. Mice have been shown to develop hydrosalpinx, uterine cysts and dilated glandular ducts infected with Chlamydia (direct inoculation or urogenital infection) [59]. Guinea pig studies also identified a correlation between estradiol supplements and increased chlamydial disease, specifically, ascending infections resulting in endometritis, cystic salpingitis and cystitis [60].

There are clear reports indicating a difference in the physical appearance of cysts developing in koalas, and evidence of other non-infectious aetiological agents in other hosts. Considering this, future research efforts should be focused on identifying all aetiological agents for the development of koala reproductive cysts with an aim of developing new treatment regimens to allow for the recovery of female koalas. This would significantly improve the population growth of koalas with more koalas of reproductive age being released back into the wild.

Author Contributions: Conceptualisation, S.P. and M.J.; draft writing and literature search, S.P.; draft review and editing, M.J. and P.T. All authors have read and agreed to the published version of the manuscript.

Funding: This research received no external funding.

Conflicts of Interest: The authors declare no conflict of interest.

\section{References}

1. Menkhorst, P. Hunted, marooned, re-introduced, contracepted: A history of Koala management in Victoria. In Too Close for Comfort: Conentious Issues in Human-Wildlife Encounters; Lunney, D., Munn, A., Meikle, W., Eds.; Royal Zoological Society of New South Wales: Mosman, NSW, Australia, 2008.

2. Bradshaw, C.J.A. Little left to lose: Deforestation and forest degradation in Australia since European colonization. J. Plant Ecol. 2012, 5, 109-120. [CrossRef]

3. Taylor-Brown, A.; Booth, R.; Gillett, A.; Mealy, E.; Ogbourne, S.M.; Polkinghorne, A.; Conroy, G.C. The impact of human activities on Australian wildlife. PLOS ONE 2019, 14, e0206958. [CrossRef]

4. Jackson, M.; White, N.; Giffard, P.; Timms, P. Epizootiology of Chlamydia infections in two free-range koala populations. Vet. Microbiol. 1999, 65, 255-264. [CrossRef]

5. Quigley, B.L.; Timms, P. Helping koalas battle disease-Recent advances in Chlamydia and koala retrovirus (KoRV) disease under-standing and treatment in koalas. FEMS Microbiol. Rev. 2020, 44, 583-605. [CrossRef] [PubMed]

6. Nyari, S.; Waugh, C.; Dong, J.; Quigley, B.; Hanger, J.; Loader, J.; Polkinghorne, A.; Timms, P. Epidemiology of chlamydial infection and disease in a free-ranging koala (Phascolarctos cinereus) population. PLoS ONE 2017, 12, e0190114. [CrossRef] [PubMed]

7. Rhodes, J.; Ng, C.F.; de Villiers, D.L.; Preece, H.; McAlpine, C.; Possingham, H. Using integrated population modelling to quantify the implications of multiple threatening processes for a rapidly declining population. Biol. Conserv. 2011, 144, $1081-1088$. [CrossRef]

8. Santamaria, F.; Schlagloth, R. The effect of Chlamydia on translocated Chlamydia-naïve koalas: A case study. Aust. Zool. Gist. 2016, 38, 192-202. [CrossRef]

9. Blanshard Wendy, B.K. Medicine of Australian Mammals; CSIRO Publishing: Collingwood, Australia, 2008 ; p. 686.

10. Brown, A.S.; Girjes, A.A.; Lavin, M.; Timms, P.; Woolcock, J.B. Chlamydial disease in koalas. Aust. Vet. J. 1987, 64, 346-350. [CrossRef] [PubMed]

11. Larry Vogelnest, T.P. Current Therapy in Medicine of Australian Mammals; CSIRO Publishing: Collingwood, Australia, 2019.

12. Patterson, J.L.S.; Lynch, M.; Anderson, G.A.; Noormohammadi, A.; Legione, A.; Gilkerson, J.; Devlin, J. The Prevalence and Clinical Significance of Chlamydia Infection in Island and Mainland Populations of Victorian Koalas (Phascolarctos cinereus). J. Wildl. Dis. 2015, 51, 309-317. [CrossRef] [PubMed]

13. Polkinghorne, A.; Hanger, J.; Timms, P. Recent advances in understanding the biology, epidemiology and control of chlamydial infections in koalas. Vet. Microbiol. 2013, 165, 214-223. [CrossRef]

14. Phillips, S.; Quigley, B.L.; Olagoke, O.; Booth, R.; Pyne, M.; Timms, P. Vaccination of koalas during antibiotic treatment for Chlamydia-induced cystitis induces an improved antibody response to Chlamydia pecorum. Sci. Rep. 2020, 10, 10152. [CrossRef]

15. Maxie, M. Pathology of Domestic Animals, 6th ed.; Elsevier: Amsterdam, The Netherlands, 2015; Volume 3.

16. Quesenberry, K.E.; Carpenter, J.W. (Eds.) Copyright, in Ferrets, Rabbits, and Rodents, 3rd ed.; W.B. Saunders: St. Louis, MO, USA, 2012; p. ii. 
17. Tan, O.L.; Hurst, P.R.; Fleming, J.S. Location of inclusion cysts in mouse ovaries in relation to age, pregnancy, and total ovulation number: Implications for ovarian cancer? J. Pathol. 2005, 205, 483-490. [CrossRef]

18. Gupta, R.C. (Ed.) Front Matter, in Reproductive and Developmental Toxicology, 2nd ed.; Academic Press: Cambridge, MA, USA, 2017; p. iii.

19. Leanza, V.; Coco, L.; Genovese, F.; Pafumi, C.; Ciotta, L.; Leanza, G.; Zanghì, G.; Intagliata, E.; Vecchio, R. Laparoscopic removal of a giant paratubal cyst complicated by hydronephrosis. G. di Chir. J. Surg. 2013, 34, 323-325.

20. Vasilevsky, S.; Greub, G.; Nardelli-Haefliger, D.; Baud, D. Genital Chlamydia trachomatis: Understanding the Roles of Innate and Adaptive Immunity in Vaccine Research. Clin. Microbiol. Rev. 2014, 27, 346-370. [CrossRef]

21. Brunham, R.C.; Rey-Ladino, J. Immunology of Chlamydia infection: Implications for a Chlamydia trachomatis vaccine. Nat. Rev. Immunol. 2005, 5, 149-161. [CrossRef] [PubMed]

22. Ziklo, N.; Vidgen, M.E.; Taing, K.; Huston, W.; Timms, P. Dysbiosis of the Vaginal Microbiota and Higher Vaginal Kynurenine/Tryptophan Ratio Reveals an Association with Chlamydia trachomatis Genital Infections. Front. Cell. Infect. Microbiol. 2018, 8, 1. [CrossRef]

23. Rapoza, P.; Tahija, S.G.; Carlin, J.P.; Miller, S.L.; Padilla, M.L.; Byrne, G.I. Effect of interferon on a primary conjunctival epithelial cell model of trachoma. Investig. Ophthalmol. Vis. Sci. 1991, 32, 2919-2923.

24. Taylor, M.W.; Feng, G.S. Relationship between interferon-gamma, indoleamine 2,3-dioxygenase, and tryptophan catabolism. FASEB J. 1991, 5, 2516-2522. [CrossRef] [PubMed]

25. Madden, D.; Whaite, A.; Jones, E.; Belov, K.; Timms, P.; Polkinghorne, A. Koala immunology and infectious diseases: How much can the koala bear? Dev. Comp. Immunol. 2018, 82, 177-185. [CrossRef]

26. Mathew, M.; Beagley, K.W.; Timms, P.; Polkinghorne, A. Preliminary characterisation of tumor necrosis factor alpha and interleukin-10 responses to Chlamydia pecorum infec-tion in the koala (Phascolarctos cinereus). PLoS ONE 2013, 8, e59958. [CrossRef]

27. Mathew, M.; Pavasovic, A.; Prentis, P.J.; Beagley, K.W.; Timms, P.; Polkinghorne, A. Molecular characterisation and expression analysis of Interferon gamma in response to natural Chlamydia infection in the koala, Phascolarctos cinereus. Gene 2013, 527, 570-577. [CrossRef]

28. Mathew, M.; Waugh, C.; Beagley, K.W.; Timms, P.; Polkinghorne, A. Interleukin 17A is an immune marker for chlamydial disease severity and pathogenesis in the koala (Phascolarctos ci-nereus). Dev. Comp. Immunol. 2014, 46, 423-429. [CrossRef]

29. Islam, M.M.; Jelocnik, M.; Huston, W.M.; Timms, P.; Polkinghorne, A. Characterization of the In Vitro Chlamydia pecorum Response to Gamma Interferon. Infect. Immun. 2018, 86. [CrossRef]

30. Canfield, P.J. A mortality survey of free range koalas from the north coast of New South Wales. Aust. Vet. J. 1987, 64, 325-328. [CrossRef] [PubMed]

31. Obendorf, D. Pathology of the Female Reproductive Tract in the Koala, Phascolarctos cinereus (Goldfuss), from Victoria, Australia. J. Wildl. Dis. 1981, 17, 587-592. [CrossRef]

32. Canfield, P.J.; Oxenford, C.J.; Love, D.N.; Dickens, R.K. Pyometra and pyovagina in koalas. Aust. Vet. J. 1983, 60, 337-338. [CrossRef] [PubMed]

33. Fabijan, J.; Woolford, L.; Lathe, S.; Simmons, G.; Hemmatzadeh, F.; Trott, D.; Speight, N. Lymphoma, Koala Retrovirus Infection and Reproductive Chlamydiosis in a Koala (Phascolarctos cinereus). J. Comp. Pathol. 2017, 157, 188-192. [CrossRef]

34. Higgins, D.P.; Hemsley, S.; Canfield, P.J. Association of Uterine and Salpingeal Fibrosis with Chlamydial Hsp60 and Hsp10 Antigen-Specific Antibodies in Chlamydia -Infected Koalas. Clin. Vaccine Immunol. 2005, 12, 632-639. [CrossRef]

35. Hemsley, S.; Canfield, P.J. Histopathological and immunohistochemical investigation of naturally occurring chlamydial conjunctivi-tis and urogenital inflammation in koalas (Phascolarctos cinereus). J. Comp. Pathol. 1997, 116, 273-290. [CrossRef]

36. Brown, A.S.; Carrick, F.N.; Gordon, G.; Reynolds, K. The Diagnosis and Epidemiology of an Infertility Disease in the Female Koala: Phascolarctos cinereus (Marsupialia). Vet. Radiol. 1984, 25, 242-248. [CrossRef]

37. Speight, K.N.; Polkinghorne, A.; Penn, R.; Boardman, W.; Timms, P.; Fraser, T.; Johnson, K.; Faull, R.; Bate, S.; Woolford, L. Prevalence and Pathologic Features of Chlamydia Pecorum Infections in South Australian Koalas (Phascolarctos cinereus). J. Wildl. Dis. 2016, 52, 301-306. [CrossRef]

38. Canfield, P. A survey of urinary tract disease in New South Wales koalas. Aust. Vet. J. 1989, 66, 103-106. [CrossRef] [PubMed]

39. Department of Environment and Science. Care of Sick, Injured or Orphaned Protected Animals in Queensland. D.o.E.a.S. Wild-Life and Threatened Species Operations Branch. Queensland Government. 1992. Available online: https://www.qld.gov. au/_data/assets/pdf_file/0022/202198/cp-wl-rehab.pdf (accessed on 29 August 2021).

40. Marschner, C.; Flanagan, C.; Higgins, D.; Krockenberger, M.B. Validation of ultrasonography in detecting structural disease of the urogenital tract of the koala, Phascolarctos cinereus. Aust. Vet. J. 2014, 92, 177-178. [CrossRef]

41. Bernuci, M.P.; Szawka, R.; Helena, C.; Leite, C.; Lara, H.E.; Anselmo-Franci, J.A. Locus Coeruleus Mediates Cold Stress-Induced Polycystic Ovary in Rats. Endocrinology 2008, 149, 2907-2916. [CrossRef]

42. Kang, X.; Jia, L.; Shen, X. Manifestation of Hyperandrogenism in the Continuous Light Exposure-Induced PCOS Rat Model. BioMed Res. Int. 2015, 2015, 943694. [CrossRef] [PubMed]

43. Abbott, D.; Rayome, B.; Dumesic, D.; Lewis, K.; Edwards, A.; Wallen, K.; Wilson, M.; Appt, S.; Levine, J. Clustering of PCOS-like traits in naturally hyperandrogenic female rhesus monkeys. Hum. Reprod. 2017, 32, 923-936. [CrossRef] [PubMed] 
44. Arifin, E.; Shively, C.A.; Register, T.C.; Cline, J.M. Polycystic Ovary Syndrome with Endometrial Hyperplasia in a Cynomolgus Monkey (Macaca fascicularis). Vet. Pathol. 2008, 45, 512-515. [CrossRef]

45. Vanholder, T.; Opsomer, G.; De Kruif, A. Aetiology and pathogenesis of cystic ovarian follicles in dairy cattle: A review. Reprod. Nutr. Dev. 2006, 46, 105-119. [CrossRef] [PubMed]

46. Zulu, V.C.; Sawamukai, Y.; Nakada, K.; Kida, K.; Moriyoshi, M. Relationship among Insulin-Like Growth Factor-I, Blood Metabolites and Postpartum Ovarian Function in Dairy Cows. J. Vet. Med. Sci. 2002, 64, 879-885. [CrossRef]

47. Rey, F.; Rodriguez, F.; Salvetti, N.; Palomar, M.; Barbeito, C.; Alfaro, N.; Ortega, H. Insulin-Like Growth Factor-II and Insulin-Like Growth Factor-Binding Proteins in Bovine Cystic Ovarian Disease. J. Comp. Pathol. 2010, 142, 193-204. [CrossRef]

48. Knauf, Y.; Bostedt, H.; Failing, K.; Knauf, S.; Wehrend, A. Gross Pathology and Endocrinology of Ovarian Cysts in Bitches. Reprod. Domest. Anim. 2014, 49, 463-468. [CrossRef]

49. Szulańczyk-Mencel, K.; Rzasa, A.; Bielas, W. Relationships between ovarian cysts and morphological and hormonal state of ovarian cortex in sows. Anim. Reprod. Sci. 2010, 121, 273-278. [CrossRef]

50. Jan, M.H.; Das, G.; Singh, J.; Khan, S. Oxidative stress during cystic ovarian disease in water buffalo. Indian J. Anim. Sci. 2015, 85, 356-360.

51. Park, J.H.; Choi, T.S. Polycystic ovary syndrome (PCOS)-like phenotypes in the d-galactose-induced aging mouse model. Biochem. Biophys. Res. Commun. 2012, 427, 701-704. [CrossRef]

52. Ho, S.-C.; Liu, J.-H.; Wu, R.-Y. Establishment of the mimetic aging effect in mice caused by D-galactose. Biogerontology 2003, 4, 15-18. [CrossRef] [PubMed]

53. Song, X.; Bao, M.; Li, D.; Li, Y.M. Advanced glycation in d-galactose induced mouse aging model. Mech. Ageing Dev. 1999, 108, 239-251. [CrossRef]

54. Patisaul, H.B.; Mabrey, N.; Adewale, H.B.; Sullivan, A.W. Soy but not bisphenol A (BPA) induces hallmarks of polycystic ovary syndrome (PCOS) and related metabolic co-morbidities in rats. Reprod. Toxicol. 2014, 49, 209-218. [CrossRef]

55. Rubio, A.; Boyen, F.; Tas, O.; Kitshoff, A.; Polis, I.; Van Goethem, B.; De Rooster, H. Bacterial colonization of the ovarian bursa in dogs with clinically suspected pyometra and in controls. Theriogenology 2014, 82, 966-971. [CrossRef]

56. Bozdag, G.; Mumusoglu, S.; Zengin, D.; Karabulut, E.; Yildiz, B.O. The prevalence and phenotypic features of polycystic ovary syndrome: A systematic review and meta-analysis. Hum. Reprod. 2016, 31, 2841-2855. [CrossRef] [PubMed]

57. Wehrend, A.; Failing, K.; Hauser, B.; Jäger, C.; Bostedt, H. Production, reproductive, and metabolic factors associated with chlamydial seropositivity and reproductive tract anti-gens in dairy herds with fertility disorders. Theriogenology 2005, 63, 923-930. [CrossRef]

58. Videla, C.; Carballal, G.; Kekiklian, G.; Juárez, C.; Gómez, M.M.; Filippo, E.; García, A. Chlamydia trachomatis and tubal obstruction sterility. Medicine 1994, 54, 6-12.

59. Sun, X.; Yang, Z.; Zhang, H.; Dai, J.; Chen, J.; Tang, L.; Rippentrop, S.; Xue, M.; Zhong, G.; Wu, G. Chlamydia muridarum Induction of Glandular Duct Dilation in Mice. Infect. Immun. 2015, 83, 2327-2337. [CrossRef] [PubMed]

60. Rank, R.G.; White, H.J.; Hough, A.J.; Pasley, J.N.; Barron, A.L. Effect of estradiol on chlamydial genital infection of female guinea pigs. Infect. Immun. 1982, 38, 699-705. [CrossRef] [PubMed] 